\title{
Promoting Indigenous nursing student success in post-secondary education: A phenomenological study
}

\author{
Twana Cox-White, Beverlee Ziefflie, Heather Joyce Nelson* \\ Instructor Practical Nursing, Saskatchewan Polytechnic, Canada
}

Received: June 26, 2019

Accepted: July 15, 2019

Online Published: July 28, 2019

DOI: $10.5430 /$ jnep.v9n10p101

URL: https://doi.org/10.5430/jnep.v9n10p101

\begin{abstract}
Background and aim: Indigenous students have a lower rate of post-secondary completion than non-Indigenous students. This is due to a variety of intrinsic and extrinsic factors. Current literature revealed a variety of concerns that were naturally divided under the themes of academic preparedness, cultural safety, intrinsic student factors, and student supports. This study examined the completion rates of Indigenous students within a nursing program, student associated success strategies, and predominant personal barriers to success. Using focus groups and interviews, the researchers examined the lived experiences Indigenous students at Saskatchewan Polytechnic in Western Canada.

Methods: A qualitative design using a phenomenological approach was utilized to gather data. Focus groups and interviews with Indigenous students were conducted to gather personal perspectives and experiences. This data was then coded and themed.

Results: The results of this study identified various strategies and supports that advanced and promoted Indigenous student success along with numerous barriers that Indigenous students felt impeded their success within the nursing program at Saskatchewan Polytechnic. The themes in this study included academic preparedness, cultural safety, resolve/resilience, confidence, social expectations, and financial support.

Conclusions: There is a need to expand and develop support systems that enable Indigenous students to improve academic completion rates. Building confidence and a sense of belonging are important factors in improving student success from post-secondary programs
\end{abstract}

Key Words: Indigenous, Students, Nursing, Post-Secondary, Barriers, Success

\section{INTRODUCTION}

"Education is what got us into this mess-the use of education at least in terms of residential schools-but education is the key to reconciliation. "[1] -Justice Murray Sinclair

Justice Murray Sinclair spoke these profound words after releasing his findings of the Truth and Reconciliation Commission (TRC) of Canada Report. ${ }^{[2]}$ As educators, embracing and responding to the TRC Calls to Action that directly address post-secondary institutions and the education of health care providers within Canada is essential. ${ }^{[2]}$ As
non-Indigenous researchers, it was important for us to recognize our biases, consult with Indigenous leaders, and open our minds to an Indigenous worldview. Understanding and gaining awareness about the differences between a western worldview, recognized and supported within most academic institutions, and observing, gaining, and understanding the view through an Indigenous lens and perspective was imperative.

One important aspect examined was the role of equity and equality for Indigenous students. There is an important and

\footnotetext{
*Correspondence: Heather Joyce Nelson; Email: heather.nelson@ saskpolytech.ca; Address: Instructor Practical Nursing, Saskatchewan Polytechnic, Canada.
}

Published by Sciedu Press 
profound difference between these terms. Equality is treating every student the same and this is a significant step on the continuum of cultural understanding. Equity is a step farther on the continuum; acknowledging that everyone does not enter a program with the same background or supports and requires differing institutional provisions, ensures that everyone has the same opportunity to complete a program. Instructors have a duty to recognize that treating all students equally is not necessarily synonymous with fair. Students require a level playing field so that they have every opportunity to succeed. Beyond equality, there is equity, an important distinction when it comes to Indigenous students.

Indigenous students enter the nursing program with different levels of academic preparedness and different cultural experiences. They often face barriers that simply do not exist for non-Indigenous students. ${ }^{[3]}$

Forty-nine per cent of Indigenous students complete postsecondary education compared to 65 per cent of nonIndigenous students. ${ }^{[4]}$ This is in part, due to the fact that attrition rates are higher for indigenous students. ${ }^{[5]}$ The gap is even more significant at the level of university completion, with 11 per cent of Indigenous people holding university degrees compared to 29 per cent for non-Indigenous people. ${ }^{[4]}$ Education level is particularly important because there is a direct correlation between level of education and employment rate. Indigenous people holding a high school diploma have an unemployment rate of 11.4 per cent, while those with college or trades education have an unemployment rate of 7.7 per cent and university graduates have an unemployment rate of 3.5 per cent. ${ }^{[6]}$

Educational institutions face ongoing challenges to retain and support all students. This challenge is particularly evident for Indigenous students. This study examined the lived experiences of Indigenous nursing students and particularly focused on positive supports and barriers to successful program completion.

For the purpose of this article, the term Indigenous is used as opposed to Aboriginal. "Indigenous" includes First Nations, Métis, and Inuit peoples. ${ }^{[7]}$ At some points, various participants have referred to themselves as First Nations, Aboriginal, or Native and these terms remained as quoted.

\section{MATERIALS AND METHODS}

\subsection{Study design}

A multi-method approach to qualitative research was used combining interviews, a focus group, and surveys. Posters were placed in central areas of the Practical Nursing (PN) program. A poster was also placed on the online notice board. Between 2016 and 2019, twelve Indigenous students partic- ipated in personal interviews or a focus group. All but one participant completed a survey.

\subsection{Participants}

A total of 12 Indigenous students participated in either personal interviews or a focus group. The participants' ages ranged from 17-45+ with four between the ages of 17-24, 4 between the ages of 25-34, 2 between 35-44 and one participant older than 44. Eight students self-identified as First Nations and 3 self-identified as Métis. All participants were female.

\subsection{Setting}

The study was conducted in the Saskatchewan Polytechnic School of Nursing, Practical Nursing Program. Practical nursing is a two-year diploma program. On completion, students are eligible to become Licensed Practical Nurses. The Practical Nursing Program in Regina, Saskatchewan, Canada accepts forty-four students per year and aims to have 16 per cent with Indigenous ancestry. This meets that mandate of Saskatchewan Polytechnic to align with the percentage of Indigenous peoples in Saskatchewan.

\subsection{Measures}

One focus group and eight interviews were conducted. Semistructured questions were utilized to enable participants to discuss their particular concerns while ensuring the same categories of data were collected from all participants.

Each participant was also asked to complete a demographic survey. This survey was used in determining age, cultural background, educational background, social support, number of children, and self-identification within Indigenous culture.

\subsection{Data analysis}

The interviews were transcribed and de-identified by a professional transcriptionist. Data was then assigned a code and themed by hand. Three individuals performed this coding and theming to improve reliability. The researchers independently reviewed the de-identified transcripts of an interview and focus group participants. Each reviewer themed the data according to their perspective and understanding of the data. The reviewers then compared and contrasted the findings and created common themes.

\section{RESULTS}

The focus group and interview data were divided into six themes: academic preparedness, cultural safety, resolve/resilience, confidence, social expectations, and financial support. Each of the themes could be a support or a barrier depending on their presence or absence. 


\subsection{What is success?}

The goal of the researchers was to identify success strategies and barriers to student success rates. Academic institutions typically defined success as program completion. The researchers realized that everyone's definition of success is not the same. Therefore, the first question asked of the participants was, "What is success to you?"

For the participants, success included several factors. Academic success was one feature but success within self, family, and community were equally important. Each participant desired to successfully complete the program and establish a nursing career. Some participants were concerned with achieving high averages, while others felt that marks were unimportant and passing the program was the goal.

The concept of giving back to community was mentioned by multiple participants. Two participants' goals were to seek employment on a reserve helping other Indigenous people. Family was also a large factor in success for the participants, "If I can maintain my relationships with my family because it is not that great now that I've started school. I feel like I haven't seen them or like they feel like I am neglecting them." Safety for themselves and their families was also important for several participants. For one participant, staying sober for herself and her family was the biggest success.

Success was very personal and was reflected in selfconfidence. One participant stated success was, "To feel like I'm finally good enough.” Another participant defined success as, "finding fulfillment in every aspect - mental, emotional, spiritual, and physical." A third participant reiterated this sentiment, "That would be a huge success for me to believe in myself."

While academic success was important, it was essential to be mindful that academic success was only one definition and that success was a multi-faceted concept.

\subsection{Academic preparedness}

While the literature pointed to academic preparedness as a significant factor contributing to success, it did not show as strongly in our primary research. ${ }^{[8-10]}$ Some students felt prepared while others felt that their high school education was lacking in some areas. Many participants were concerned about workload expectations in the post-secondary environment. One of the participants stated, "The teachers on my reserve were really good for preparing us." Some participants, however, felt that high school preparation was inadequate, particularly with respect to composition, writing skills, and test preparation. Of note, survey results showed that two participants attended reserve schools and two participants completed adult upgrading. The rest of the participants attended public high schools.

The students' feelings of preparedness did not match with the researchers' experience in the classroom, the students' postsecondary academic results, or the literature. ${ }^{[8-10]}$ This could be due to a number of factors, such as, lack of awareness by the students' regarding academic expectations and interviewing many of the students at the beginning of the year before they were academically challenged in post-secondary school. Additionally, some of the participants performed well academically in post-secondary education, therefore, their feelings of preparedness were founded.

\subsection{Cultural safety}

The feeling of safety, security, and support related to culture and traditions was another theme found within the data. A feeling of cultural safety was present for some participants and lacking for others. More frequently, participants had experienced incidences of both positive and negative cultural safety in their lifetime and in their school experience. Each of the students saw their cultural identity in different lights. For some, it was very important and for others, it was something they wanted to conceal.

The participants lived experiences and the views of their families influenced how they perceived their culture. The survey showed that five students considered themselves involved or very involved with their Indigenous culture, three considered themselves somewhat involved and three considered themselves not very involved or not involved at all. This is a subjective measure and two students who regularly attended Indigenous cultural events and spent much time on reserve viewed themselves as being only somewhat involved in their culture.

Participants who strongly identified with their culture recognized it as a source of strength. One participant said, "Living as a First Nation's woman every day is important to me. Smudging, going to ceremonies, getting back into painting or starting to make my outfit for dancing, my culture is what gets me by." One of the participants did not feel as connected with her culture due to her families past experiences. "Grandma was a residential school survivor and mom was adopted out". Another participant stated that some of her fellow Indigenous students failed academically due to addictions, family problems, and mental health issues. She stated, "It all stems from, I am not going to lie, residential schools." These experiences affected how students felt about themselves and how they viewed their Indigenous heritage. The effects of intergenerational trauma were evident in many of the participant's responses.

Students experienced racism, which affected their sense of 
self-worth and trust in the educational system and society. One participant stated, "I don't like to admit I am Indigenous because others may think I get preferential treatment such as an Indigenous seat in the program and everything paid for." Some participants indicated that they felt like they were "not fitting in with the white crowd but not fitting in with other Indigenous peoples." One participant stated, "I look too white." For some participants, the journey through the program was also a journey in self and cultural growth Indigenous ceremonies held by the institution, as well as Indigenous activities in the classroom, were seen as significant for these participants.

\subsection{Resolve/resilience}

At the beginning of this study, the researchers erroneously felt that Indigenous students often lacked resilience as compared to non-Indigenous students. This was due to some Indigenous students not following typical educational procedures and expectations, leading to low or failing grades and high rates of attrition. These behaviours included missing mandatory classes, submitting assignments after the due dates, and failing to adhere to program policies. In reality, the complex challenges faced by many Indigenous students related to home life, cultural expectations, and social pressures is truly what demonstrated their resilience and determination. Their resilience was displayed through their continued attendance and completion of classes despite major challenges.

For some, acceptance into a nursing program required a great deal of resilience. "[I] felt like giving up in the application process," stated one participant. Another stated, "I think it is quite common for First Nations People if you don't get in the first try then, oh well, it's not going to be." An institutional counselor told one participant that nursing was not the right choice because she had children. The post-secondary application process can be complicated. Many participants were the first generation to attend a post-secondary institute so family members often did not have the experience to assist with the application process.

After admittance to the program some participants continued to struggle with the belief that they belonged. Often, the Indigenous students reported that they had reoccurring and pervasive thoughts that they did not deserve to be a postsecondary student. "My first month I just cried and cried and cried and wanted to quit and I had one good, good friend who kept telling me to just keep going." Another participant commented, "I still think about quitting every other day." The fact that these participants continued in the program, despite physical and emotional setbacks and barriers, demonstrated resilience.

\subsection{Confidence}

Confidence was a key ingredient in obtaining success within the nursing program. Participants expressed that confidence was a struggle that led to negative thought patterns. In one instance, a participant stated, "I have to believe that it is OK to be Native." Another participant needed to "[Allow] myself to feel good about the things I do and why I'm here." Some of the participants' family members were unsuccessful in post-secondary education, therefore, they struggled to believe that successful completion was possible. "I need to believe in myself," voiced a third participant. One student, who expressed her need to feel confidence, reiterated, success was “To feel like I'm finally good enough.” While all participants felt that belief in oneself was vital to success, confidence was an ongoing challenge.

\subsection{Social expectations}

Many of the participants were involved with their extended families and large social groups. This was a support to students but the time required to maintain these relationships was an added stressor. Participants explained that, as family members and members of their community, they were often expected to spend extensive time with their family and friends, which interfered with their studying. For example, if there was a death in the extended family, they were expected to take up to a week off to attend the wake, traditional prayers, feasts, and the funeral. Students had to navigate between two different cultures with different expectations. Adhering to the Indigenous cultural expectations could result in negative consequences within the educational environment. Attempting to meet the expectations related to post-secondary education, could have negative consequences within their family and social group.

Academically successful students made themselves a priority. In the Indigenous culture, the priority is often being a good family member or friend. It is hard to put those expectations on the back burner and focus on school. In the words of one participant, "I'm neglecting my family and stuff but just having some time to myself, to have some time to think, is a big thing." Pressures included, "kids, trying to be a good wife and a good mother, and feeling like I am always falling short." Another stated, "I never get to see my kids as much and I don't get to see my friends as much, or my family or basically anyone." One participant discussed her feelings of growing up in a house with addictions. "It's just like, you grow up in a house that's not really healthy and that's the kind of adult you become and it's hard to have priorities, especially priorities such as nursing school." The survey of the participants showed that Indigenous students often had children. Three students had no children, two students had one 
child, two students had two children, two students had three children and two students had four or more children. Balancing social and cultural obligation with academic expectations was a constant struggle.

\subsection{Financial support}

There is a misconception that Indigenous students are fully funded for all post-secondary education, but this is not the case. Participant funding ranged from full and partial band funding to self-funding and student loans. Participants explained that there is often a disconnect and gap between the timing of band funding applications and acceptance into school. They are often accepted into school after the date to apply for band funding has expired, leaving many students not funded or underfunded. Indigenous students who have not successfully completed post-secondary education in the past may not be eligible for ongoing or future band funding and at times, they do not meet student loan requirements. Finally, band funding is inconsistent and students must apply each year. Receiving funding for one year of a program does not ensure funding will be continued for the remainder of the program.

Several participants received band funding and were thankful for this financial support. Other participants did not receive any funding and the difficulty meeting their financial commitments were added pressures. One participant was "trying to work until $2: 30$ in the morning and come to school at 8:30, surviving on coffee and energy drinks to get through." Another participant stated the challenge was "lack of money and lack of supplies for school." Half of the students worked to meet their financial obligations during the year. The participant survey indicated that five of the students did not work during the school year and six of the students worked throughout the school year. It is often suggested by educators that students not work or limit working hours to be successful at school, but this is not always possible.

\section{Discussion}

This study adds to the body of information supporting Indigenous student success showing that Indigenous students had the same struggles as every other student but often had additional social, financial and self-perception issues. One important thing to note is that Indigenous people are not a homogenous group. There are many Indigenous nations with different cultures, traditions, and values. Within these nations, each individual experience is unique. This study represents the experiences of 12 individuals and does not attempt to represent the experience of Indigenous peoples as a whole. Within this study, there were Indigenous students that required little to no support by the institution to be successful

Published by Sciedu Press and other students who required a variety of supports.

A significant finding was the role of self-confidence and self-perception on successful program completion. Selfconfidence grows throughout the program with each successful skill test and exam completion. The question is how do we promote this early in the program to prevent early attrition. Often students do not arrive in the program with supports in place and these supports are only added after students are unsuccessful on exams and assignments. This further decreases students' self-esteem and makes it difficult for students to catch-up.

It has been documented that many Indigenous peoples have experienced tragic and devastating experiences due to the Residential School systems, and a lack of trust and intergenerational trauma clearly remain. ${ }^{[2]}$ Many Indigenous students have experienced racism and are experiencing unique social pressures and barriers. ${ }^{[3,11]}$ Given that all three researchers are of European descent, Indigenous experiences and perceptions are not part of our lived experience. Not having lived these experiences we believe that it is particularly important to build relationships to promote a level of instructor-student trust; without this, open dialogue is not possible.

In Saskatchewan Polytechnic, there is still a lack of Indigenous instructors. Hiring Indigenous instructors within the educational institution is imperative. These individuals may not only be viewed as role models by Indigenous students but may create and promote a sense of safety and cultural acceptance. All instructors need to learn and embrace the strengths and barriers that many Indigenous students continue to face today. Gaining an understanding of Indigenous history, culture, and traditions will facilitate an understanding, bridging the gap and drawing attention to both the strengths and struggles of today's Indigenous people.

\subsection{Study limitations}

The sample size of this study was 12 . This represents approximately $57 \%$ of the potential participants. This does not include those students who do not self-declare their Indigenous ancestry. Further interviews may provide valuable data. Additionally, the study was done in Regina and the study results may not be transferable to other institutions in other areas. We acknowledge that students at different schools may have a completely different experience based on the supports and faculty at each school.

The focus group and interviews were completed at various times throughout the academic year which may have impacted the results. Students at the start of the year may not have understood the barriers they would face in the program. Additionally, the interviewers had not built a relationship 
with the students, therefore, the students may not have been as willing to share.

While none of the interviewers had an evaluative role with those they interviewed, and this was clearly outlined to students, some participants may not have felt safe to honestly answer the questions for fear it may affect their academic evaluation. Also, the participants may have been less willing to share due to the fact that researchers were non-Indigenous.

\subsection{Gaps/need for future study}

Research with an increased sample size will lend stronger credibility to the results. Participants from nursing programs outside of Regina, Saskatchewan could be interviewed to give a more complete perspective. Further research should include the interventions and the effectiveness of these interventions.

\section{CONCLUSION}

Indigenous participants define success in a multifaceted way. The definition of success is a byproduct of culture, in this case, a culture heavily influenced by a difficult history filled with challenges and limited opportunity. Studying the strengths, success mechanisms, and barriers of Indigenous student success is a first step to better support Indigenous students and all students.

There is a tremendous opportunity to learn more about the histories and lifestyle of Indigenous peoples and the challenges and barriers they face in completing post-secondary education. While our goal is to create equity, we are not there yet.

\section{Conflicts of InTEREST Disclosure}

The authors declare that there is no conflict of interest.

\section{REFERENCES}

[1] Sinclair M. Truth and reconciliation chair urges Canada to adopt UN declaration on Indigenous peoples. 2015. Available from: https://www.cbc.ca/news/politics/truth-and-reconci liation-chair-urges-canada-to-adopt-un-declaration -on-indigenous-peoples-1.3096225

[2] National Centre for Truth and Reconciliation. Truth and Reconciliation Commission Final Report. 2015. Available from: http: //www.trc.ca/about-us/trc-findings.html

[3] Best O, Stuart L. An Aboriginal nurse-led working model for success in graduating Indigenous Australian nurses. Contemporary Nurse: A Journal for the Australian Nursing Profession. 2014; 48(1): 59-66. https://doi.org/10.1080/10376178.2014.11081927

[4] Statistics Canada. Table 37-10-0099-01 Distribution of the population aged 25-64 (total and with Aboriginal identity), by highest certificate, diploma or degree and age group. 2016. Available from: https://www150.statcan.gc.ca/t1/tbl1/en/tv.act ion?pid=3710009901

[5] Gallop CJ, Bastien N. Supporting Success: Aboriginal Students in Higher Education. The Canadian Journal of Higher Education. 2016; 46(2): 206-224.
[6] Statistics Canada. Table 41-10-0036-01 Unemployment rates of population aged 15 and over, total and with Aboriginal identity, by educational attainment, Canada. 2018. Available from: https ://www150 . statcan.gc.ca/t1/tbl1/en/tv. action?pid=1410036101

[7] Parrott Z. Indigenous peoples in Canada. In the Canadian Encyclopedia. 2018. Available from: https://www. thecanadianencyclo pedia.ca/en/article/aboriginal-people

[8] Foxall D. Barriers in Education of Indigenous Nursing Students: A Literature Review. Nursing Praxis in New Zealand. 2013; 29(3): 33-39.

[9] Slovacek S, Whittinghill J, Flenoury L, et al. Promoting Minority Success in the Sciences: The Minority Opportunities in Research Programs at CSULA. Journal of Research in Science Teaching. 2012; 49(2): 199-217. https://doi.org/10.1002/tea. 20451

[10] Slatyer S, Cramer J, Pugh JD, et al. Barriers and enablers to retention of Aboriginal. Nurses Education Today. 2016; 42: 17-22. PMid:27237347 https://doi.org/10.1016/j.nedt. 2016.03 .026

[11] Gilmon ME. Cultural diversity and the experiences of Alaska Native nursing students. University of Northern Colorado. 2012. 